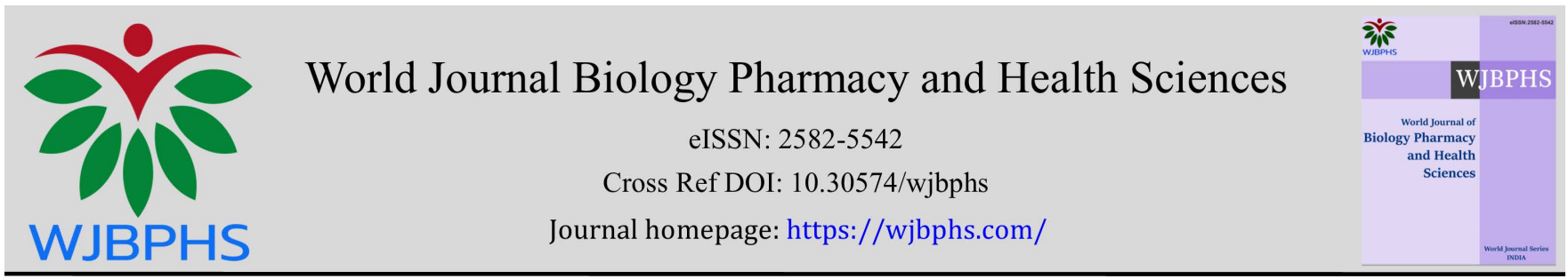

(RESEARCH ARTICLE)

\title{
Callahan's thought field therapy in the management of emotions associated with stress
}

\section{Fernando Vicente Barraza-Alvarez *}

Faculty of Agricultural Sciences of the University of Córdoba. Carrera 6 No. 77- 305, Montería, Córdoba, Colombia.

World Journal of Biology Pharmacy and Health Sciences, 2021, 07(02), 060-068

Publication history: Received on 10 July 2021; revised on 14 August 2021; accepted on 16 August 2021

Article DOI: https://doi.org/10.30574/wjbphs.2021.7.2.0085

\begin{abstract}
Taking into account that Thought Field therapy (TFT) is a non-invasive technique for managing emotions, and that it is characterized by being safe and fast, it was applied in a group of 14 people from the workforce of the Center of Childhood Integration and Connivance "Del Bosque", Texсосо, Mexico, who voluntarily expressed some feelings associated with stress before an initial interview, in order to evaluate their effectiveness. $36 \%$ of the participants reported presenting anxiety; 29\% fear; $21 \%$ obsession, and 14\% rejection. Once the TFT was completed, these emotions, in all the participants, went from a maximum rating of 10 Units of Discomfort Sensation (UDS) to a minimum of 0 UDS, so it could be established that the TFT technique was effective in managing stressful situations that were to be eradicated, with written opinions that expressed satisfaction on the part of the participants, who had no adverse reactions when the technique was applied to them.
\end{abstract}

Keywords: Tapping; Complementary medicines; Acupressure techniques; Meridian points

\section{Introduction}

Currently, the users of health services are faced with a variety of medical systems, enriched by the ethnic and cultural diversity of the communities, which has given way for people to decide in the choice of non-traditional therapeutic alternatives such as acupuncture and homeopathy, using them more and more in an increasing way [1] [2] [3].

In the antagonistic relationships that have occurred between Western medicine and complementary medicines, it is necessary to indicate that it is not a matter of choosing between one and the other, so it is better to consider the latter as an important complement to official medicine, since that no medicine or therapy replaces the other [3] [4].

Complementary medicines seek health by balancing the mind, body and soul, looking at the human being in a holistic way [2] [3].

For traditional Chinese medicine, emotions are correlated with various diseases, which are a consequence of the inadequate flow of the vital force that circulates through precise points in the body, which are located in fourteen channels or basic meridians, corresponding to the fundamental organs, through which vital energy or Chi is distributed throughout the body. With one of its main practices, such as acupuncture, the rebalancing of the vital energy system is favored, through the insertion of needles in the precise points mentioned, achieving a return to internal and external harmony, balance is rediscovered, and therefore in health [4] [5] [6].

Based on traditional Chinese medicine, the American psychologist Roger Callahan developed the alternative therapy called Thought Field Therapy (TFT), which differs from acupuncture in that it does not use needles for its treatment.

\footnotetext{
* Corresponding author: Fernando Vicente Barraza-Alvarez. E-mail: fbarraza@correo.unicordoba.edu.co

Professor at the Faculty of Agricultural Sciences of the University of Córdoba. Carrera 6 No. 77- 305, Montería, Córdoba, Colombia. 
Through acupressure techniques ("tapping") with the fingers, on the meridian points, mainly on the top of the head and the palms of the hands, various physical ailments, mental states and a wide variety of psychological conditions and phobias ca be cured [4] [5] [6] [7].

One of the most internationally recognized institutions that has given its prestige and professional career for defending complementary medicines is the Universidad Autónoma Chapingo, through the Department of Phytotechnics, with its University Program of Traditional Medicine and Naturopathic Therapeutics and University Program of Ornamental Horticulture, has promoted research, elective subjects, courses, diplomas and postgraduate courses in some streams classified as complementary medicines, among which is TFT [4] [8].

Taking into account that the TFT stands out for its rapid application, rapid results, absence of invasion to patients, economy, ease of learning, teaching and the possibility of self-application, with this research the objective was to evaluating, from the University Program of Traditional Medicine and Naturopathic Therapeutics of the Universidad Autónoma Chapingo, the results of the application of TFT therapy in personnel assigned to the Center for Integration and Child Connivance "Del Bosque", SC, Community Neighborhood Nursery No. U-1327 of the Mexican Social Security Institute.

\section{Material and methods}

A quasi-experimental investigation was carried out in the nursing unit of the "Del Bosque" Childhood Integration and Connivance Center, S.C., Community Neighborhood Nursery No. U-1327 of the Mexican Social Security Institute, located in Texcoco, Mexico. Through the qualitative method, with the participant observation technique, an informative socialization was carried out on the foundation, application form, scope and expected results with the completion of the TFT.

By means of a semi-structured interview of voluntary choice to know the willingness of the personnel to participate in the application of the test, out of a total of 19 people of female biological sex, 14 participants were selected with ages between 19 and 47 years.

Subsequently, each of the participants signed an Informed Consent document, based on the Official Mexican Standard NOM-004-SSA3-2012, which included as relevant information the topics such as: the nature of the TFT, its objectives, benefits, risks, inconveniences and possible side effects, including those derived from not carrying out the treatment and the possibility of freely withdrawing consent when desired [9].
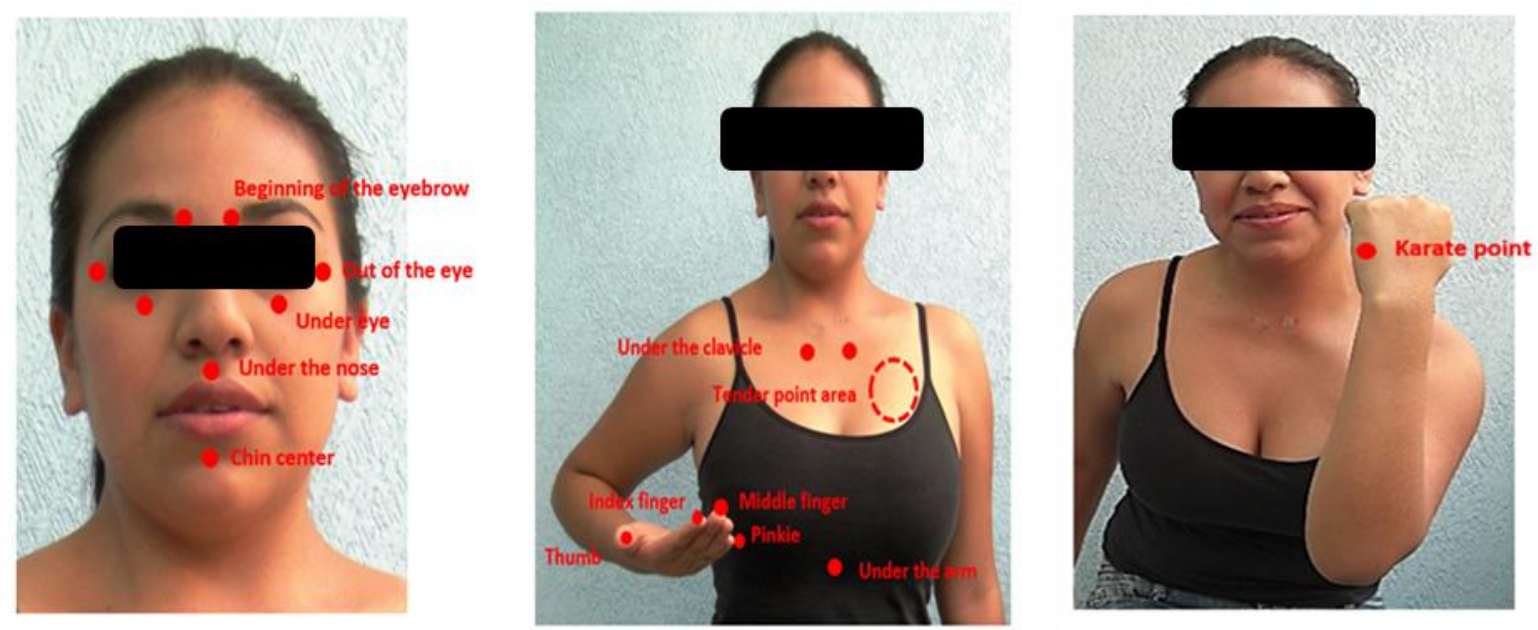

Figure 1 Major and minor acupuncture points for application of TFT

To perform the TFT, the following sequence was applied: 1- "tapping" (massage or light blow with the index finger) on the major acupuncture points, for 30 seconds; 2 - "tapping" on the minor acupuncture points, for 30 seconds; 3 -sequence 9 Gama and 4-brain gymnastics exercise [6] [9]. 
The major acupuncture points are: beginning of the eyebrow (cc: Zanzhu or V.2), outside the eye (fo: Tongziliao or VB1), under the eye (o: Chengqi or E.1), under the nose (bn: Shuigou or Du.26) and center of the chin (m: Chengjiang or Ren.24).

The minor acupuncture points are: under the arm (b: in men Ruzhohg or E.17, and in women Rugen or E.18), under the clavicle (c: Shufu or R.27) and points of the hand: thumb (Shaoshang or P.11), index finger (di: Shangyang or IG1), middle finger (Zhongchong or PC9), little finger (dm: Shaochong or C.9) and karate point (Houxi or ID3). In addition, to somatize the emotions, the painful point area will be used, also known as the sensitive point or psychological inversion point, IP (Quihu or E.13). Figure 1.

The steps followed by the person to perform the TFT were the following: [10]

- Express the emotion to be treated. Example: anger. Here the Callahan algorithm for the specific emotion is assigned, which includes the points to be tapped. All major and minor points were worked on for a more complete therapy [10] [11] [12] [13].

- Quantify emotion through UDS. Example: 10. It is a way of quantifying the degree of annoying emotion that the patient experiences. They can be measured on a scale from zero to ten [7].

- Make a phrase expressing how you feel. Example: "I am very angry because I cannot express my ideas."

- Somatize the emotion: say the elaborated phrase aloud and think about the emotion. At the same time, perform a gentle massage with the middle and index fingers, to the painful point, (Figure 2). This step is repeated three times. For example: "I am very angry because I cannot express my ideas. I accept it completely, I appreciate and respect myself as I am".

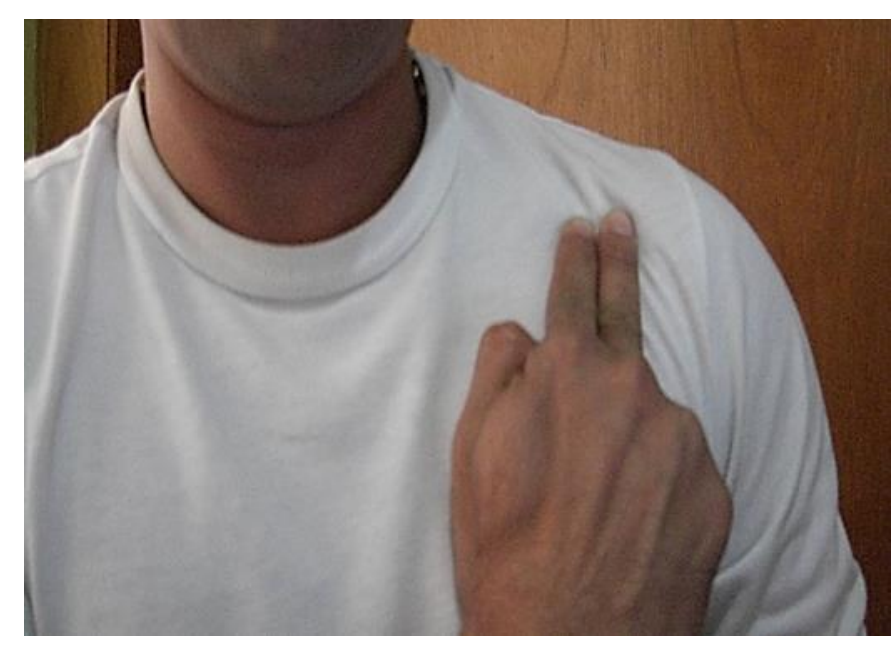

Figure 2 Massage of the painful point, while the patient expresses the phrase

- Tapping the major points of the body, one by one, while repeating the phrase elaborated on the subject at hand.

- Hit the minor points of the body, one by one, including the karate point (Figure 3), while repeating the phrase. Here it is important that you say the part of the phrase: “... I accept it completely, or I appreciate and respect myself as I am".

- Breathe gently for two minutes.

- Assign a new grade to the emotion. In the event that the new qualification drops more than two points with respect to the initial one, the 9 range procedure is carried out. If the new score does not drop more than two points, the indicated sequence is repeated, from steps four to seven, and additionally, the specific psychological investment must be worked on, with the tapping of the karate point, while repeating some phrase such as: "I'm less angry now, I accept it, I want to feel better."

- $\quad$ The 9 Gamma sequence consists of nine consecutive steps, while tapping the Gamma point (g; corresponds to the Zhongzhu point of the hand, S.J.3, Figure 4): a) Close your eyes; b) Open your eyes; c) Move your eyes down and to the side; d) Move the eyes down and to the other side; e) Roll the eyes in a circle in one direction; f) Roll the eyes in a circle in the opposite direction; g) Hum a melody (approximately five notes) with your mouth closed; h) Count from one to five out loud; i) Hum the melody again with your mouth closed. 
- Brain gymnastics: the technique of eyes rolling from floor to ceiling was done, in which the patient while tapping on the Gama point and keeping his head at his level, looks down slowly counting to 10 . The gaze is rolled over the floor, the wall and the ceiling, as high as possible.

- Drink water.

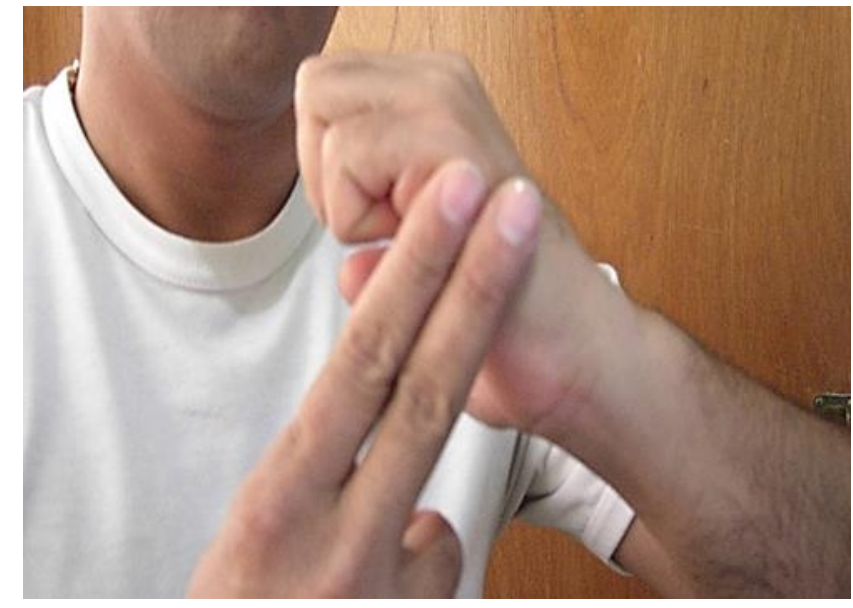

Figure 3 Tapping the karate point

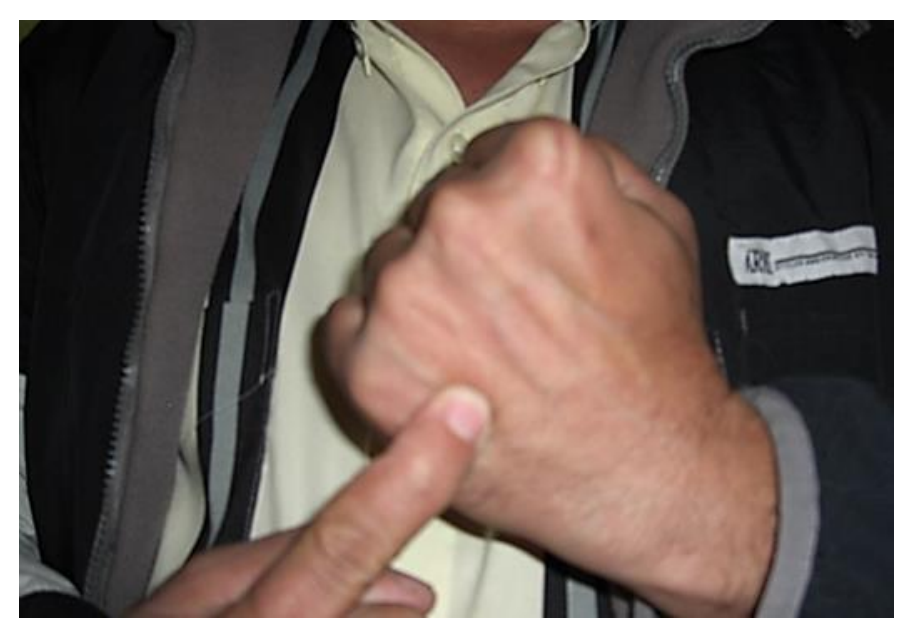

Figure 4 Tapping of the Gamma point

To determine the acceptability of the TFT in terms of the characteristics of its rapidity in its performance, effectiveness and credibility by the patients, once it was completed, a five-point hedonic test was performed:

\section{Score Category}

- I extremely dislike

- I moderately dislike

- I neither like nor dislike

- I like it moderately

- I like it extremely

With the data obtained, an analysis of variance (ANOVA) was performed with a significance level of $p \leq 0.05$. Additionally, each patient filled out in writing their general assessment of the results obtained once the TFT was completed. 


\section{Results and discussion}

Table 1 Information on 14 patients from the "Del Bosque" Childhood Integration and Connivance Center, S.C., Texcoco, México

\begin{tabular}{|c|c|c|c|c|c|c|}
\hline Patient & Gender & Age (years) & $\begin{array}{l}\text { Referred } \\
\text { problem }\end{array}$ & $\begin{array}{l}\text { Initial qualification } \\
\text { (UDS) }\end{array}$ & $\begin{array}{l}\text { Final } \\
\text { qualification (UDS) }\end{array}$ & $\begin{array}{l}\text { Callahan } \\
\text { algorithm }\end{array}$ \\
\hline 1 & $\mathrm{~F}$ & 20 & Obsession & 10 & 0 & $\mathrm{C}-\mathrm{O}-\mathrm{C}$ \\
\hline 2 & $\mathrm{~F}$ & 31 & Obsession & 9 & 0 & $\mathrm{C}-\mathrm{O}-\mathrm{C}$ \\
\hline 3 & $\mathrm{~F}$ & 39 & Obsession & 9 & 0 & C-O-C \\
\hline 4 & $\mathrm{~F}$ & 29 & Fear & 10 & 0 & $b-o-c$ \\
\hline 5 & $\mathrm{~F}$ & 38 & Fear & 10 & 0 & b-o-c \\
\hline 6 & $\mathrm{~F}$ & 36 & Fear & 10 & 0 & b-o-c \\
\hline 7 & $\mathrm{~F}$ & 26 & Fear & 10 & 0 & b-o-c \\
\hline 8 & $\mathrm{~F}$ & 27 & Anxiety & 8 & 0 & $0-b-c$ \\
\hline 9 & $\mathrm{~F}$ & 29 & Anxiety & 10 & 0 & o-b-c \\
\hline 10 & $\mathrm{~F}$ & 22 & Anxiety & 10 & 0 & o-b-c \\
\hline 11 & $\mathrm{~F}$ & 47 & Anxiety & 10 & 0 & o-b-c \\
\hline 12 & $\mathrm{~F}$ & 19 & Anxiety & 10 & 0 & o-b-c \\
\hline 13 & $\mathrm{~F}$ & 22 & Rejection & 10 & 0 & cc-o-b-c \\
\hline 14 & $\mathrm{~F}$ & 24 & Rejection & 10 & 0 & cc-o-b-c \\
\hline
\end{tabular}

F: female; UDS: Units of Discomfort Sensation on a scale from 0 to 10; c: under the clavicle, o: under eye, b: under the arm, cc: beginning of the eyebrow

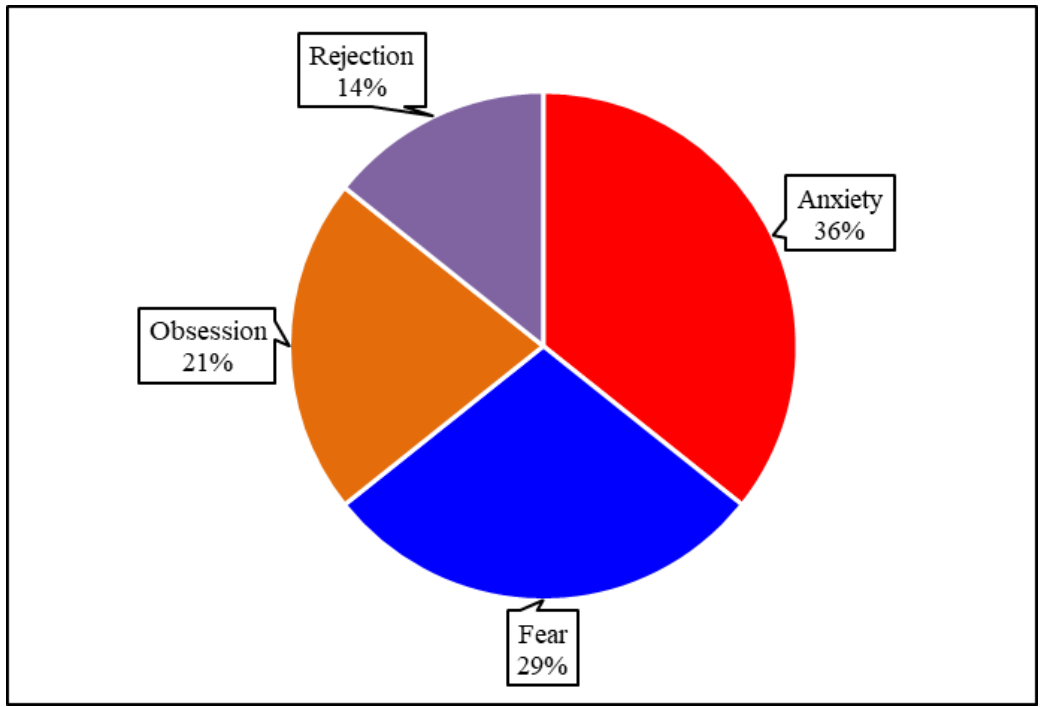

Figure 5 Percentage distribution of the feelings expressed in the group of patients

Table 1 presents the information on the emotions indicated by the patients, UDS scores and assigned algorithms. It was found that the feeling of anxiety was the one that most occurred among the participants, followed by fear, obsession and rejection (Figure 5). Based on the registered UDS, all feelings were affected in people in a range between 80 and $100 \%$.

The ANOVA showed that there were no statistical differences between the appraisals of the TFT by the participants, with regard to the characteristics of rapidity in its performance, effectiveness and credibility (Table 2), with mean values close to the maximum score, in accordance with the scale used (Figure 6). 
Table 2 ANOVA for the acceptance, rapidity in the realization, effectiveness and credibility of the TFT applied to patients of the Center for Integration and Childhood Connivence "Del Bosque", S.C., Texcoco, México

\begin{tabular}{|l|c|c|l|l|c|}
\hline \multicolumn{7}{|l|}{ VS } & \multirow{2}{*}{ DF } & SS & \multirow{2}{*}{ MS } & \multicolumn{2}{|l|}{ Relation of F } \\
\cline { 3 - 6 } & & & & Calculated & Tabular \\
\hline Characteristics & 2 & 0,001429 & 0,000714286 & $0,056 \mathrm{~ns}$ & 3,176 \\
\hline Patients & 13 & 0,64 & 0,049029304 & & \\
\hline Error & 54 & 0,69 & 0,012813051 & & \\
\hline \multicolumn{7}{|c|}{69} & & & & \\
\hline Total & VS: variation source; DF: degrees of freedom; SS: sum of squares; MS: mean square; ns: not significant
\end{tabular}

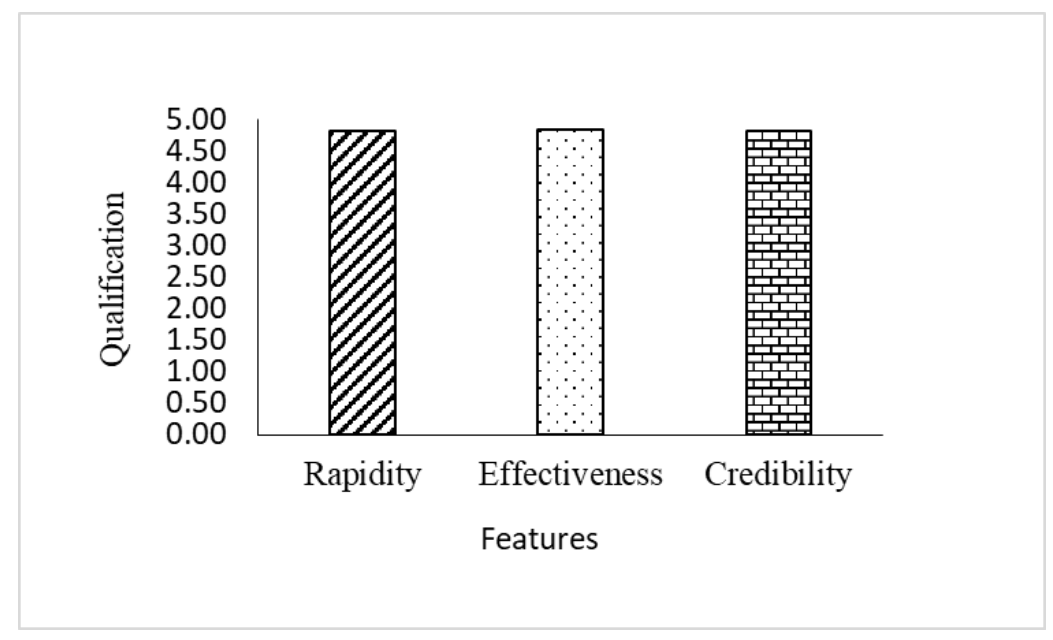

Figure 6 Average score \pm standard deviation of TFT features

With the random selection of the written opinions expressed by the patients in each of the reported emotions, the following was found:

\subsection{Obsession}

Patient No. 3: "I experienced relaxation and tranquility. Now I have a lot of courage. I feel happy and wanting to move on".

\subsection{Fear}

Patient No.6: "After the therapy I felt relaxed and in a better state of health, since I felt bad and with muscle pain, joint pain and headache."

\subsection{Anxiety}

Patient 12: "I felt that a part of me was removed, since I am very sensitive. I feel like a weight has been lifted off my shoulders. I needed it. I am at rest".

\subsection{Rejection}

Patient No.13: "I feel like I no longer care about some people's criticism and attacks towards me. This was so suddenly and I already feel free".

The manifestations of rapid eradication of stress situations, expressed by all the patients, reflect that the central objective of the TFT was achieved, since in accordance with Edwards and González [7] and Callahan [14], the "tapping 
"of the major and minor acupuncture points provides a code to eliminate emotional anguish from the causes that constitute its root, which is based on the fact that the body, feelings and mind are not separate entities, and that according to Amador [15], constitute a total unit, in such a way that what the mind causes, the mind can heals.

In addition to the above, in accordance with Amador [15] and Ibarra [16], the brain gymnastics exercises carried out by the patients, contributed to our being able to use all our mental capacities, in order to achieve self-balance, which is based on mainly in that they help us to create neural networks that multiply the alternatives to respond to the different situations presented, allowing a healthier development of our organism, and that our unconscious thoughts accept what the conscious is ordering them.

The importance of the written reports collected in this research, about the positive perception of patients towards TFT, lies in the fact that they validate the approaches of Sakai et al. [17], in the sense that said information constitutes an input to carry out the verification and follow-up, as well as the self-evaluation of patients who have significantly reduced the emotional burden of suffering and stress produced by the memory of traumatic and post-traumatic events , leading to increasingly identify emotions that can be added to the treatment list with TFT, in addition to constituting, according to Irgens et al. [18], supporting documents for their promotion and defense.

However, for Feinstein [18], after a critical analysis of 51 scientific articles about TFT, it is confirmed as an energy psychology technique that uses exposure and cognitive restructuring, integrating according to Craig [13], the entry of kinetic energy to the meridians of the body by the stimulation of acupuncture points, with verbal procedures that produce changes quickly and effectively for a series of conditions based on anxiety, trauma, phobia and post-traumatic stress, which corroborates the validity of the rapid and excellent results obtained with the patients who participated in the present investigation.

On the other hand, Irgens et al. [19] point out that several detractors of TFT have used it, achieving success in its application when other therapies did not produce results. The cases of McNally [20] and Herbert and Gaudiano [21], who have obtained promising results, are mentioned as relevant.

Despite the fact that Pignotti [22] stood out as an important opponent of TFT, after her skepticism towards the technique, she has reported its growth, diffusion and popularity through the internet and through testimonies of quick cures, which motivated her to practice it and become an author and teacher on the subject, even retracting the negative statements she made towards TFT.

In any case, according to Dyregrov [23], TFT is strengthened as research documents its rapidity of response and power, as we have been able to verify, and that for many patients it represents a safe method of reducing specific symptoms of trauma with less anguish. In this sense, it would be unethical to prevent access to this form of help, so there is an urgent need to understand how and why it works.

The expressions of relief and joy towards the results obtained with the application of TFT in the present investigation, expressed by the patients once completed, reflect the enthusiasm and empowerment reported by Nicotra [24], which becomes much more important when the results they are obtained in one go, without the need to repeat the procedure, and more importantly, when other types of therapies have not worked for the patient.

\section{Conclusion}

When applying the TFT, it was possible to experience and establish the obtaining of rapid and satisfactory results in the entire study population, regarding the achievement of the objectives of eradicating the negative emotions manifested and returning to each person a state of happiness and liberation, evidenced in their minimum final UDS grade and the ability to impartially express their positive opinion about the experience, which validates its effectiveness.

\section{Compliance with ethical standards}

\section{Acknowledgments}

The author acknowledges the Universidad de Córdoba and Universidad Autónoma Chapingo management, teachers, non-teaching staffs, and colleagues for their kind support. 


\section{Disclosure of conflict of interest}

The author declares no conflict of interest regarding publication of this article.

\section{Statement of informed consent}

Informed consent was obtained from all individual participants included in the study.

\section{References}

[1] Menéndez E. (1994). La enfermedad y la curación. ¿Qué es medicina tradicional? Alteridades, 4(7): 71-83.

[2] Duarte Gómez MB. (2003). Medicina occidental y otras alternativas: ¿es posible su complementariedad? Reflexiones conceptuales. Cad. Saúde Pública, 19(2): 635-643.

[3] García Consuegra F. (2016). Estudio de opinión sobre preferencias de los pacientes en la escogencia entre la medicina tradicional y alternativa en la ciudad de Barranquilla. Dictamen Libre, 19: 17-32.

[4] Mendoza Castelán G. (2008). Las medicinas complementarias en México, First edition. Programa Universitario de Medicina Tradicional y Terapéutica Naturista. Departamento de Fitotecnia. Universidad Autónoma Chapingo, Texcoco, México, 16-19.

[5] Editorial Época SA, de CV. (2005). Acupuntura básica, DF, México, 29-30.

[6] Jun Z y Jing Z. (2007). Localización de los puntos acupunturales. First edition. Editorial del Instituto Latinoamericano de Medicina Oriental. Sección de estudio y enseñanza de acupuntura y moxibustión del Instituto de la Medicina Tradicional China de Beijing, D.F., México, 36-58.

[7] Edwards J y González L. (2006). Terapia de Campo Mental. Manual de Capacitación a Nivel de Algoritmos. Association for Thought Field Therapy. Callahan Techniques Ltd., California, U.S.A., 42-53.

[8] Mendoza Castelán G y Lugo Pérez R. (2010). Farmacia viviente. Conceptos, reflexiones y aplicaciones. Programa Universitario de Medicina Tradicional y Terapéutica Naturista. Universidad Autónoma Chapingo. Departamento de Fitotecnia, Texcoco, México, 20-26.

[9] Alonso Que HT, Aja Canales J, Castillo Uribe, L y Rodríguez Delgado NA. (2015). El consentimiento informado en la actualidad, su evolución y el punto de vista del experto jurídico. Anales de Radiología México, D.F, 14: 172-177.

[10] Mollon P. (2007). Thought Field Therapy and its derivatives: Rapid relief of mental health problems through tapping on the body. Primary care and community psychiatry, 12(3-4): 123-127.

[11] Ojeda Ríos M. (2008). Par Biomagnético. Programa Universitario de Medicina Tradicional y Terapéutica Naturista. Universidad Autónoma Chapingo. Departamento de Fitotecnia, Texcoco, México, 53-68.

[12] Callahan JM. (2010). Programa diario de reducción del estrés. Técnicas Callahan. Terapia del Campo Mental. La terapia del siglo XXI, Miami, USA, 3-5.

[13] Craig G. (2018). La increíble técnica EFT. La iluminación espiritual. Biblioteca de espiritualidad y sabiduría, Miami, USA, 7-12.

[14] Callahan RJ. (2001). The Impact of Thought Field Therapy on Heart Rate Variability (HRV). Journal of Clinical Psychology, 57(10): 1153-1170.

[15] Amador Pizá AE. (2006). Guía Práctica de Gimnasia Cerebral. First edition. Random House Mondadori, S.A. de C.V., D.F., México, 121-139.

[16] Ibarra LM. (2005). Aprende Mejor con Gimnasia Cerebral. 16 ed. D.F., Garnik Ediciones, D.F., México, 16-22.

[17] Sakai CE., Connolly SM. and Oas P. (2010). Treatment of PTSD in Rwandan Child Genocide Survivors Using Thought Field Therapy. International Journal of Emergency Mental Health, 12(1): 41-50.

[18] Feinstein D. (2012). Acupoint stimulation in treating psychological disorders: Evidence of efficacy. Review of General Psychology, 16(4): 364-380.

[19] Irgens AC, Hoffart A, Nysæter TE, Haaland VØ, Borge FM, Pripp AH, Martinsen EW and Dammen T. (2017). Thought Field Therapy compared to cognitive Behavioral Therapy and Wait-List for Agoraphobia: A Randomized, Controlled Study with a 12-Month Follow-up. Front. Psychol., 8: 1-14.

[20] McNally R J. (2001). Tertullian's motto and Callahan’s method. J. Clin. Psychol., 57(10): 1171-1174. 
[21] Herbert JD, Gaudiano B A. (2001). The search for the Holy Grail: heart rate variability and thought field therapy. J. Clin. Psychol., 57(10): 1207-1214.

[22] Pignotti M. Thought Field Therapy: A Former Insider's Experience. Research on Social Work Practice, 17(3): 392407.

[23] Dyregrov A. (2015). Thought Field Therapy-not something that the cat dragged in? Scandinavian Psychologist, 2(2): $1-10$

[24] Nicotra Clemente T. (2009). The experience of social workers who use thought field therapy or emotional freedom technique. Master of Science thesis, Smith College School for Social Work, Massachusetts, USA, 8-22. 